\title{
A histological study on the development of the digestive system of Pseudosciaena crocea larvae and juveniles
}

\author{
KANGSEN MAI ${ }^{1 *}$, HAIRUI YU ${ }^{1}$, HONGMING MA ${ }^{1}$, QINGYUAN DUAN ${ }^{1}$, ENRIC. GISBERT ${ }^{2,3}$, \\ JOSÉ.L. ZAMBONINO INFANTE ${ }^{2}$ AND CHANTAL.L. CAHU ${ }^{2}$
}

\footnotetext{
${ }^{1}$ Key Laboratory of Mariculture, Education Ministry of China, Ocean University of China, Qingdao 266003, China.

${ }^{2}$ Unité Mixte INRA-IFREMER de Nutrition des Poissons, Centre de Brest, BP 70, 29280 Plouzané, France.

${ }^{3}$ Centre d'Aqüicultura, Institut de Recerca i Tecnologia Agroalimentàries (IRTA), Apdo. Correos 200, 43540 Sant

Carles de la Ràpita, Spain.

*: Corresponding author : +86-532-8978083; fax: +86-532-2032495; e-mail: kmai@ouc.edu.cn
}

\begin{abstract}
The ontogenetic development of the digestive tract and accessory organs in large yellow croaker (Pseudoscianea crocea) was described using light microscopy from hatching up to the juvenile stage (40 days post hatch, dph). At $3 \mathrm{dph}(4.10 .1 \mathrm{~mm}$ total length, LT), coinciding with the buccopharynx opening, larvae started to feed exogenously, and the digestive tract consisted of a welldeveloped buccopharynx, a partially-differentiated oesophagus, and an intestine divided in three regions (prevalvular and postvalvular intestine, and rectum). Yolk reserves were not completely depleted at the onset of exogenous feeding, and a period of mixed nutrition was observed up to $6 \mathrm{dph}$ (4.3 $0.1 \mathrm{~mm} \mathrm{LT}$ ), when yolk was definitively exhausted. Important morphological changes occurred at the end of the larval period, coinciding with metamorphosis. At $17 \mathrm{dph}\left(\begin{array}{l}6.8 \\ 0.6 \mathrm{~mm} \mathrm{LT}\end{array}\right)$, pyloric caeca differentiated at the junction of the pyloric stomach and the prevalvular intestine. Gastric glands were firstly observed at $21 \mathrm{dph}(9.2 \quad 1.2 \mathrm{~mm} \mathrm{LT})$, coinciding with the morphological development of the stomach in three different regions (cardiac, fundic and pyloric) according to the histological characteristics of their mucosa. At this age, large longitudinal folds appeared in the median and posterior oesophageal mucosa. These morphological and histological features suggested the achievement of a digestive system characteristic of large yellow croaker juveniles and adults.
\end{abstract}

Keywords: large yellow croaker; Pseudoscianea crocea; development; digestive system; histology 


\section{INTRODUCTION}

The large yellow croaker (Pseudoscianea crocea, Richardson), a sciaenid, is a benthopelagic temperate fish species distributed along the Northwest Pacific coast (Masuda et al., 1984). This species supports important commercial fisheries in the Yellow and East China Seas, and it is one of the most relevant aquaculture species in China in terms of fingerling production. The number of artificially produced fry of large yellow croaker has increased from 1995 to 2000 (1.3 billion of fry), as well as the number of hatcheries dedicated to its production (400 along the northeastern coast in the Fujian Province) (Hong \& Zhang, 2003). Production at a large scale of large yellow croaker fry in commercial Chinese hatcheries still relies on traditional rearing protocols based in feeding larvae with live preys (rotifers brine shrimp nauplii and copepods). However, the substitution of a compound diet for live preys is crucial for lowering production costs and for sustaining production of high and constant quality juveniles (Cahu \& Zambonino infante, 2001). In these sense, different studies are being carried out in order to better understand the digestive physiology of young large yellow croaker and formulate an inert artificial diet to cope with nutrient demands, and successfully replace live feed by artificial diets.

In marine fish aquaculture, all too often, trial and error practices take the place of a thorough biological understanding of the factors that facilitate success or failure (Hamlin et al., 2000). The knowledge of the ontogenetic digestive tract differentiation associated with food digestion and assimilation processes is essential for understanding the nutritional physiology of larval fish, and synchronise the physiological stage of development with feeding practices and rearing protocols. A detailed understanding of the development of the digestive tract may help to reveal limiting factors in rearing protocols, reducing bottlenecks in larvae culture and weaning processes. These kind of studies, coupled with enzymatic studies, represent an initial step for the identification and implementation of new feed alternatives for marine fish larvae, as well as, an 
important source of information for defining the time when the larval digestive system is functionally ready to digest and assimilate artificial feeds (Segner et al., 1993; Sarasquete et al., 1995).

The objective of this study was to describe the ontogenetic development of the digestive tract and accessory glands in large yellow croaker from hatching to metamorphosis, to achieve a better understanding of their organisation and functionality, and to provide a basis for future nutritional studies during larval rearing.

\section{MATERIAL AND METHODS}

Larvae used in the present study were obtained from routine spawning and rearing procedures at the hatchery of the National Centre for large yellow croaker in Xiangshan Bay (Ningbo, China). Larval rearing protocols used in this study were similar to those used at large scale fingerling production of large yellow croaker. After $30 \mathrm{~h}$ of incubation at $19-20^{\circ} \mathrm{C}$, large yellow croaker larvae hatched and were placed in a rearing tank (8x6x1.6 m, ca. $45 \mathrm{~m}^{3}$ in volume). During the rearing period, water temperature $\left(24 \cdot 0 \pm 1^{\circ} \mathrm{C}\right)$, dissolved oxygen $\left(8 \cdot 0 \pm 0 \cdot 2 \mathrm{mg} \mathrm{l}^{-1}\right)$, $\mathrm{pH}(8 \cdot 0 \pm$ $0 \cdot 2)$ and salinity (29.0 $\pm 3 \cdot 0)$ were regularly monitored and readjusted when needed. Fish were exposed to 12L : 12D photoperiod using overhead fluorescent lights, and light irradiance at water surface was $8.5 \mathrm{~W} \mathrm{~m}^{-2}$.

Rotifers (Brachionus plicatilis) were offered to larvae from first feeding time (3 days post hatch, dph) to $14 \mathrm{dph}$, when a combination of rotifers and Artemia nauplii was introduced into the larval rearing tank. Larvae were fed with Artemia nauplii from 14 to $28 \mathrm{dph}$, then at $21 \mathrm{dph}$ live copepods from 21 to $29 \mathrm{dph}$ and frozen copepods from 30 to the end of the study (40 dph) (Table I). Since rotifers and Artemia nauplii are naturally poor in a number of nutrients required for larval normal growth and development, especially essential polyunsaturated fatty acids (Bell 
et al., 2003), both live preys were enriched with a mixture of unicellular algae (20000-40000 cell $\mathrm{ml}^{-1}$ during the first $20 \mathrm{dph}$ ), yeast (Mauri Yeast Co. Ltd., Harbin, China) and 50DE-emulsion oil (Shangdong Marine Fisheries Research Institute, Yantai, China) (Zheng et al., 1996).

Table I. Feeding sequence for large yellow croaker larvae and early juveniles reared at $24^{\circ} \mathrm{C}$ at the hatchery of the National Centre for large yellow croaker in Xiangshan Bay (Ningbo, China).

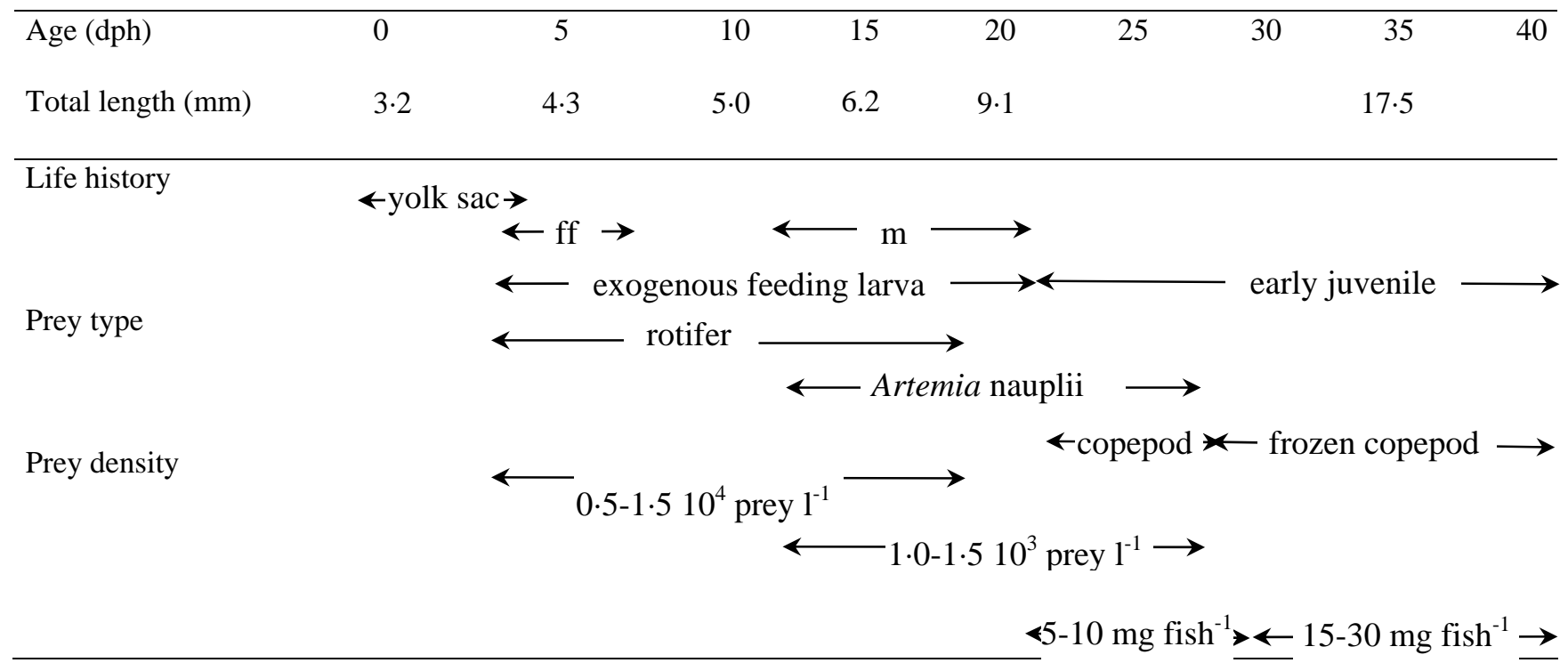

Abbreviations: ff, first feeding; m, metamorphosis. Prey proximate composition (\% dry matter, mean \pm S.D.): rotifers, proteins: $56.5 \pm 0.2$, lipids: $14.5 \pm 0.1$, ashes: $14.7 \pm 0.1$; Artemia nauplii, proteins: $39.0 \pm 0.6$, lipids: $9.6 \pm 0.2$, ashes: $24.4 \pm 0.5$; copepods, proteins: $51.3 \pm 0.4$, lipids: $8.9 \pm 0.1$, ashes: $19.3 \pm 0.3$; frozen copepods, proteins: $41.2 \pm 0.2$, lipids: $2.8 \pm 0.5$, ashes: $34.6 \pm 0.3$. Proximate composition was determined as described by the Association of Official Chemists (AOAC, 1990).

Thirty normal larvae were sampled daily from hatching to $5 \mathrm{dph}$, then every two days up to 25 dph and every 5 days until the end of the study (40 dph). Larvae were fixed with 5\% phosphate buffered formalin (pH 7.4), dehydrated in graded series of ethanol and embedded in paraffin. A serial of sagittal and cross sections $(5-7 \mu \mathrm{m})$ were cut from each paraffin block, mounted on glass slides (6-9 serial sections per slide), air dried, stained with haematoxylin and eosin (H\&E) and observed at light microscopy. 


\section{RESULTS}

At hatching, large yellow croaker larvae measured $3.2 \pm 0.1 \mathrm{~mm}$ standard length $\left(L_{\mathrm{T}}\right.$, mean \pm S.D.) and their digestive tract appeared as an undifferentiated straight tube laying dorsally to the large ovoid yolk-sac, which was not communicated with the exterior as the mouth and anus were not yet developed. At the onset of exogenous feeding, yolk-sac reserves were not completely exhausted in 3 days-old larvae $\left(4.1 \pm 0.1 \mathrm{~mm} L_{\mathrm{T}}\right)$ and a period of mixed feeding was observed just up to $6 \mathrm{dph}$, when the yolk-sac was completely absorbed and larvae depended exclusively on exogenous feeding. At this age, the digestive tract consisted of a well-developed buccopharynx, a partially-differentiated oesophagus, and an intestine divided in three regions (prevalvular and postvalvular intestine, and rectum).

From the end of the mixed feeding period up to $21 \mathrm{dph}\left(9.2 \pm 1.2 \mathrm{~mm} L_{\mathrm{T}}\right)$, major changes in the morphology and histological organisation of the digestive system in large yellow croaker were observed, i.e. folding of the oesophageal mucosa, and differentiation of gastric glands and stomach formation, and as a consequence, the digestive system changed in shape and structure resembling that of juveniles and adults.

\section{BUCCOPHARYNX}

At $3 \mathrm{dph}$, the mouth opened and larvae started feeding, and rotifers and unicellular algae were observed in their rudimentary digestive tract. At this age, the mouth presented two oral valves lined by a thick stratified columnar epithelium, while the buccal cavity was covered with a pseudostratified columnar epithelium surrounded by a thin layer of connective tissue and lamina propria. At this age, few acidophilic goblet cells and basophilic taste buds appeared scattered between the epithelial cells of the buccopharynx. Mucous cells and taste buds were visible throughout the buccopharyngeal epithelium being more abundant in the anterior region of the buccal cavity, while their size and number increased as larvae grew, especially after 7 dph. 
Between 5 and 6 dph $\left(4.3 \pm 0.1 \mathrm{~mm} L_{\mathrm{T}}\right)$ and coinciding with the end of the mixed nutrition period, canine teeth that developed in the connective tissue underlying the buccopharyngeal epithelium erupted into the buccal cavity (Fig. 1c). No changes on the histological organisation of the buccopharynx were observed until the end of the study.

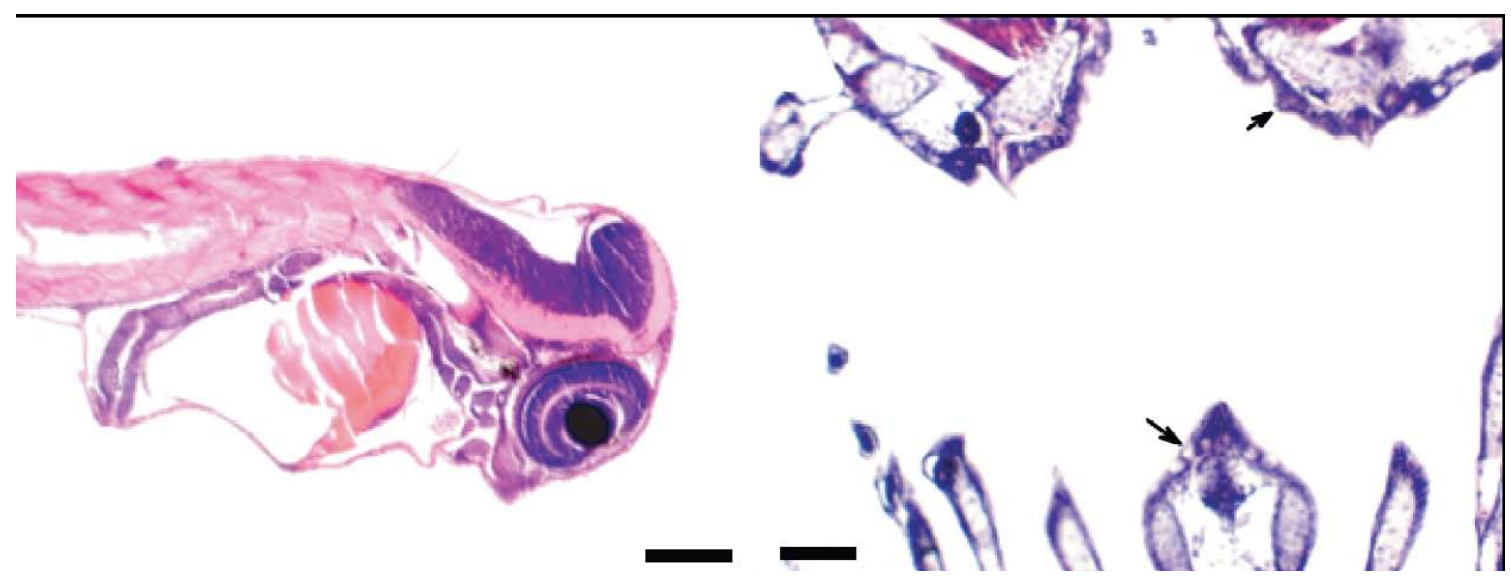

Fig. 1. Histological sections of the buccopharynx and oesophagus of large yellow croaker (H-E). (a) Sagittal section of a larva at $3 \mathrm{dph}$ with the mouth and anus opened. Scale bar $=150 \mu \mathrm{m}$. (b) Cross section of the buccopharyngeal cavity of a larva at $7 \mathrm{dph}$ showing taste buds and goblet cells. Scale bar $=60 \mu \mathrm{m}$. (c) Cross section of the buccopharyngeal cavity of a larva at $13 \mathrm{dph}$ showing a tooth. Scale bar $=60 \mu \mathrm{m}$. (d) Sagittal section of the developing oesophagus of a larva at $7 \mathrm{DAH}$. Scale bar $=60 \mu \mathrm{m}$. (e) Cross section of the forked tubers of a juvenile at $30 \mathrm{DAH}$. Scale bar $=60 \mu \mathrm{m}$. (f) Sagittal section of the oesophagus folding of a juvenile at $35 \mathrm{dph}$. Scale bar $=60$ $\mu \mathrm{m}$. A: anus; AEL: anterior oesophageal lumen; AI: anterior intestine; BA: branchial arche; BL: buccopharyngeal lumen; CM: circular musculature; CT: cartilaginous tissue; EL: oesophagus lumen; FT: oesophageal folds; GC: goblet cell; GL: gastric lumen; M: mouth; N: notochord; PEL: posterior oesophageal lumen; R: rectum; SE: stratified epithelium; SSE: stratified squamous epithelium; T: tooth; TB: taste bud; YS: yolk sac.

\section{OESOPHAGUS}

Just before the onset of exogenous feeding, a short and rudimentary oesophagus lined by a pseudostratified columnar epithelium connecting the buccopharyngeal cavity and the anterior opening of the intestine (the stomach was not differentiated at this stage) started to differentiate in yolk-sac larvae. Between 4 and $5 \mathrm{dph}$, the oesophageal mucosa was organised in a mucosa arranged in thin longitudinal folds and constituted by a stratified squamous epithelium with columnar epithelial cells and scattered acidophilic goblet cells (H\&E), a submucosa formed of a 
loose connective tissue, a wide tunica muscularis with circular and longitudinal muscle fibres and a thin serosa. At $7 \mathrm{dph}\left(4.3 \pm 0.2 \mathrm{~mm} L_{\mathrm{T}}\right)$, the oesophagus elongated and two different regions associated with mucous secretion (anterior) and feed transport functions (posterior) were clearly distinguishable. The histological organisation of the oesophageal mucosa was similar in both regions, with the exceptions of goblet cells, which were more abundant in the anterior region and the tunica muscularis, which was more developed in the posterior region of the oesophagus (Fig. 1d).

No noticeable morphological changes were observed in the oesophagus until $21 \mathrm{dph}$ (9.2 $\pm 1.2 \mathrm{~mm} L_{\mathrm{T}}$ ) when prominent longitudinal mucosal folds appeared in the posterior oesophagus, near the junction of the oesophagus and the stomach (esogaster). On the top of the oesophageal folds, the squamous epithelium was substituted by a simple columnar epithelium devoid of mucous cells. At this stage, the oesophagus acquired the characteristics of juveniles and adults.

\section{STOMACH}

The stomach was the last organ of the digestive system to differentiate. Clusters of cuboidal cells (future cardiac region) that would develop into gastric glands were visible after the end of the mixed feeding period at $7 \mathrm{dph}$ (Fig 2a).

No gastric glands were observed until 21 dph (Fig. 2b), when a Y-shaped stomach occupying the most part of the anterior abdominal region was clearly distinguishable (Fig. 2f). Three different regions were identified according to their histological organisation: the cardiac (anterior), fundic (median) and pyloric (posterior). The mucosa of the cardiac stomach was organised in folds, lined by simple short ciliated columnar epithelium with basal nuclei and devoid of goblet cells. The fundic region was lined by a simple tall ciliated columnar epithelium with acidophilic goblet cells (H\&E). Gastric glands grouped in acinar structures were distributed along the cardiac and fundic stomachal mucosa surrounded by several layers of connective 
tissue. As fish grew, the number of gastric glands increased in the fundic stomach and to a lesser extent in the cardiac region, but they were never observed in the pyloric part of the stomach (Fig. 2f). The pyloric region of the stomach was folded and lined by a short ciliated columnar epithelium and gastric glands were lacking. In a cross section, the wall of the stomach consisted of a submucosa, a lamina propria with abundant lymphocytes, a thin tunica muscularis of circular muscle fibres, and a serosa (Fig. 2e). The layer of musculature surrounding the stomach was thin in the cardiac and fundic regions but became thicker in the pyloric portion (pyloric sphincter) (Fig. 2f).

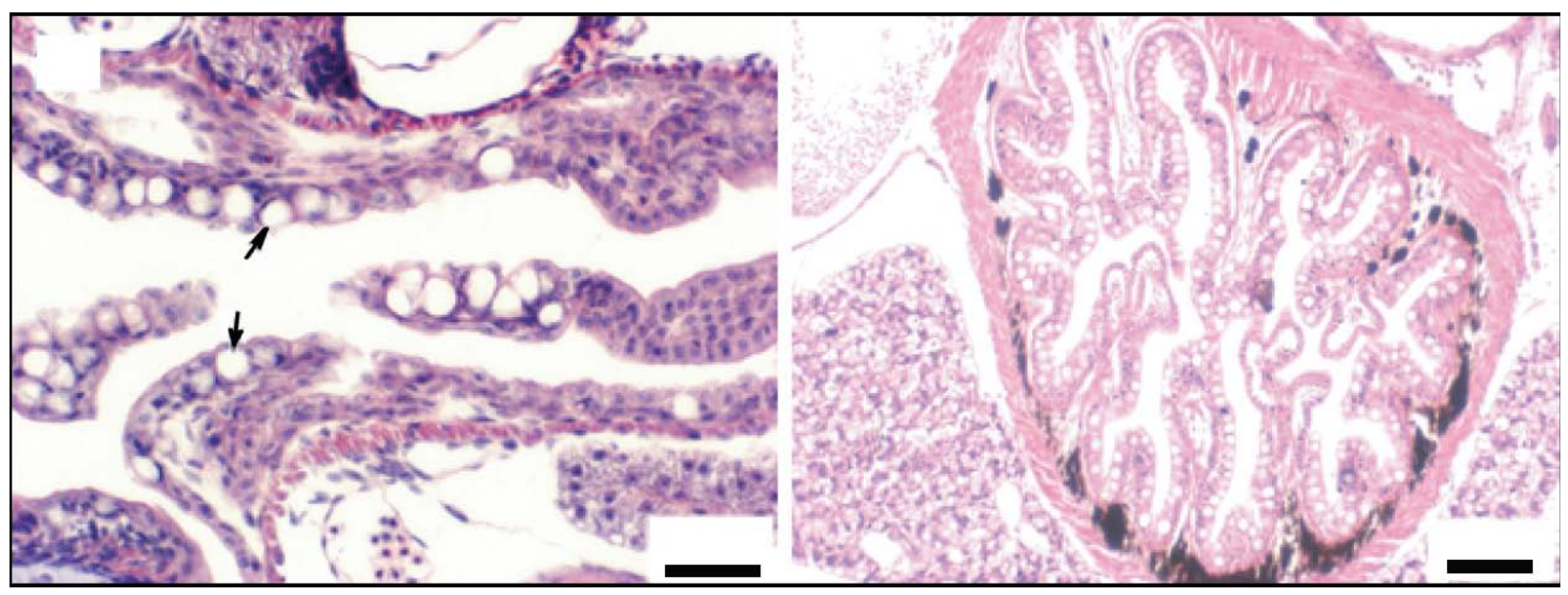

Fig. 2. Histological sections of the stomach in large yellow croaker larvae and juveniles (H-E). (a) Sagittal section of the primordial stomach of a larva at $11 \mathrm{dph}$. Scale bar $=30 \mu \mathrm{m}$. (b) Sagittal section of the stomach of a juvenile at 21 dph showing gastric glands. Scale bar $=30 \mu \mathrm{m}$. (c) Cross section of the stomach of a juvenile at 30 dph showing the cardias and pylorus. Scale bar $=150 \mu \mathrm{m}$. (d) Cross section of the cardiac stomach of a juvenile at $23 \mathrm{dph}$. Scale bar = $30 \mu \mathrm{m}$. (e) Cross section of the glandular region of a juvenile at $30 \mathrm{dph}$. Scale bar $=30 \mu \mathrm{m}$. (f) Cross section of the pyloric stomach of a juvenile at $40 \mathrm{dph}$. Scale bar $=150 \mu \mathrm{m}$. AI: anterior intestine; CC: column cell; CM: circular musculature; EL: oesophageal lumen; F: feed; GC: goblet cell; GG: gastric glands; GL: gastric lumen; GP: gastric pits; P: pyloric stomach; PA: pancreas; PC: pyloric caeca; PG: pigment granules; SCE: simple columnar epithelium; SM: submucosa.

\section{INTESTINE}

At hatching, larvae possessed a primordial intestine lined by a simple columnar epithelium in differentiation. Between 2-3 dph, the posterior region of the intestine bent $90^{\circ}$, and a constriction of the mucosa that would become the intestinal valve divided the intestine in two 
regions, the prevalvular (anterior) and postvalvular (posterior) intestine. At this age, both regions showed the same histological organisation: a simple columnar epithelium with basal nuclei bordered by a thin layer of eosinophilic microvilli at the apical surface. The postvalvular intestine terminated in a short rectal zone lined by cuboidal epithelium and deprived of folds and goblet cells.

At $5 \mathrm{dph}$, coinciding with the increase in length of the intestine, the prevalvular region convoluted in the middle part of the intestine. At the end of the mixed feeding period (7 dph), eosinophilic supranuclear vacuoles (H\&E) were observed in the postvalvular intestine of larvae, increasing in size and number as fish grew (Fig. 3e \& f). No goblet cells were detected in the intestine until $11 \mathrm{dph}$, when they were firstly detected in the prevalvular intestine and then, in the postvalvular region in larvae aged $13 \mathrm{dph}$. The number of goblet cells increased with the ontogenetic differentiation of the intestinal mucosa, being more abundant in the prevalvular intestine. At $14 \mathrm{dph}\left(5.9 \pm 0.8 \mathrm{~mm} L_{\mathrm{T}}\right)$, a pyloric ridge appeared at the junction of the stomach (pyloric sphincter) and the prevalvular intestine. This ridge was visible as a series of small pocket-like evaginations of the intestinal wall, lined by a simple layer of columnar ciliated cells with eosinophilic goblet cells (H\&E). At $17 \mathrm{dph}\left(6.8 \pm 0.6 \mathrm{~mm} L_{\mathrm{T}}\right)$, the pyloric caeca achieved their definitive finger-like shape and their number increased up to $35 \mathrm{dph}\left(17.5 \pm 2.1 \mathrm{~mm} L_{\mathrm{T}}\right)$. At this age, the convolution of the intestine was more prominent, especially in the prevalvular region. The mucosa of the prevalvular and postvalvular intestine was similar with the exception of the number and size of mucosal folds, which were more numerous and shorter in the prevalvular region. 


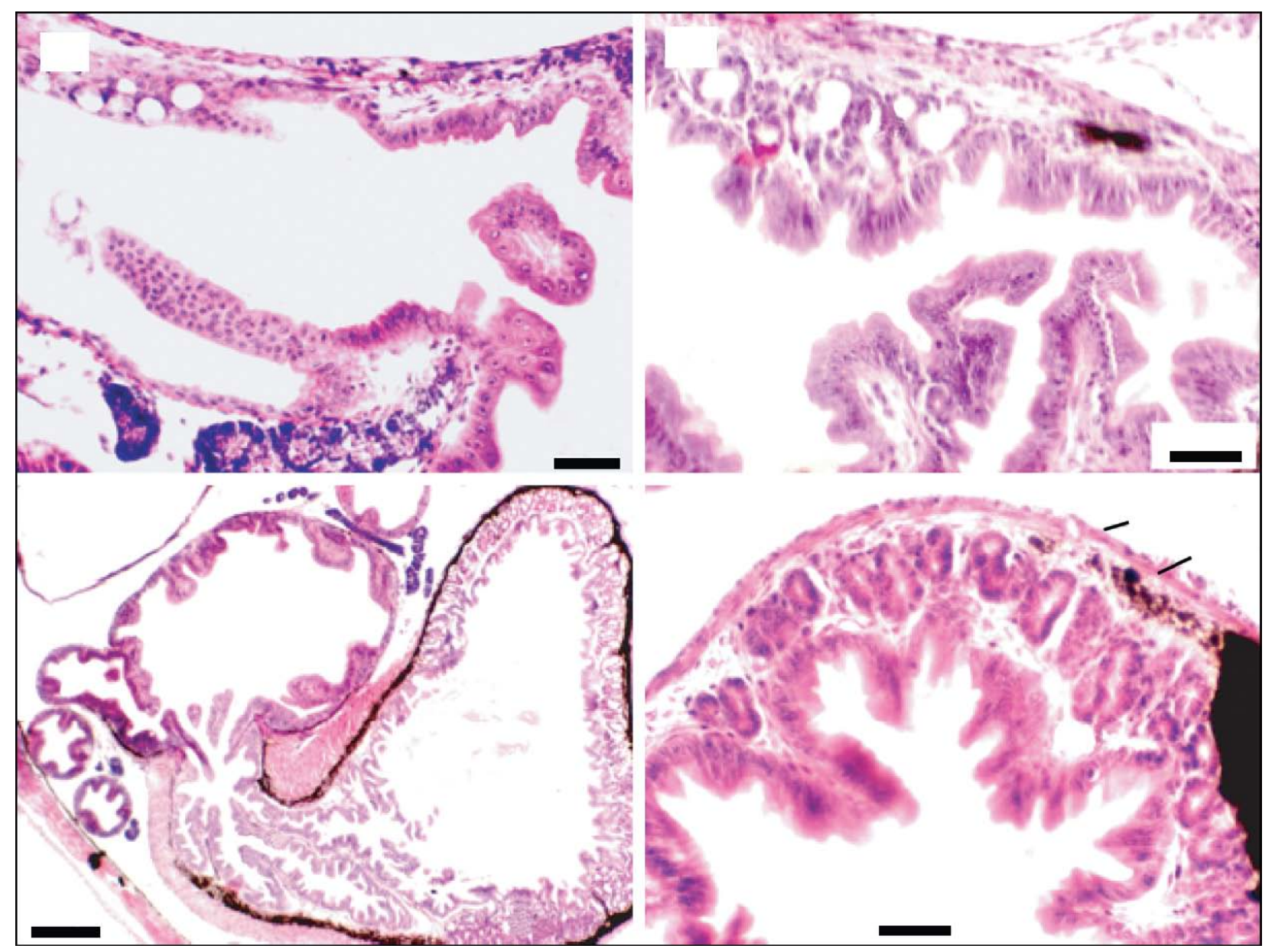

Fig. 3. Histological sections of the intestine and rectum in large yellow croaker larvae (H-E). (a) Sagittal section of a larva at $5 \mathrm{dph}$ with rests of the sac. Scale bar $=150 \mu \mathrm{m}$. (b) Sagittal section of a larva at 9 dph, showing the intestinal valve. Scale bar $=150 \mu \mathrm{m}$. (c) Sagittal section of a larva at $13 \mathrm{dph}$, showing the development of intestine and accessory glands. Scale bar $=150 \mu \mathrm{m}$. (d) Sagittal section of the anterior intestine of a larva at 7 dph, showing the simple columnar epithelium. Scale bar $=60 \mu \mathrm{m}$. (e) Cross section of the postvalvular intestine and rectum of a larva at $15 \mathrm{dph}$. Scale bar $=60 \mu \mathrm{m}$. (f) Cross section of the intestine of a larva at $19 \mathrm{dph}$ containing an almost intact decapsulated Artemia cyst. Scale bar $=30 \mu \mathrm{m}$. AI: anterior intestine; BB: brush border; BL: buccopharyngeal lumen; CC: columnar cell; EL: oesophageal lumen; F: feed; IV: intestinal valve; L: liver; MI: intermediate intestine; N: notochord; PA: pancreas; R: rectum; SCE: simple columnar epithelium; SB: swim bladder; SV: supranuclear vacuoles; YS: yolk sac.

\section{ACCESORY GLANDS}

The liver and pancreas were not differentiated at hatching. Between 2 and $3 \mathrm{dph}$, the liver and pancreas started to develop from a cluster of undifferentiated round eosinophilic cells (H\&E), and extended in the posterior region of the abdominal cavity, between the yolk sac and the postvalvular intestine (Fig. 4a). The hepatocytes were arranged loosely around a hepatic portal vein, and the liver was not divided into distinct lobules. No vacuoles were present at these 
early stages. At $5 \mathrm{dph}$, the liver became bilobulated; the right lobule was much longer and larger than the left one and protruded posteriorly. Coinciding with the onset of exogenous feeding, small vacuoles were observed in hepatocytes. As fish grew, vacuoles increased in size and occupied most part of the cytoplasm, displacing the nuclei to a peripheral position. At this time, veins, arteries and the biliar duct were present and the liver of large yellow croaker resembled to that of juveniles (Fig. 4e).

The gall bladder, lined by a simple cuboidal epithelium and externally surrounded by a thin layer of connective tissue, was distinguishable between the two lobes of the liver at 4-5 dph. As fish grew, the gall bladder became surrounded by pancreatic tissue, presenting a very wide lumen (Fig. 4c \& f).

The pancreas was diffused and mainly localised around the gall bladder, close to the liver and elongated to the prevalvular intestine. Pancreatic tissue had also invaded the liver along the hepatic portal vein and bile duct (Fig. 4e \& f). Histologically, the pancreas was arranged in acinar structures, each made up of elongated cells with basophilic cytoplasm (H\&E), supranuclear acidophilic zymogen granules (H\&E), and a prominent basally located nucleus in which the nucleolus was clearly distinguishable. 


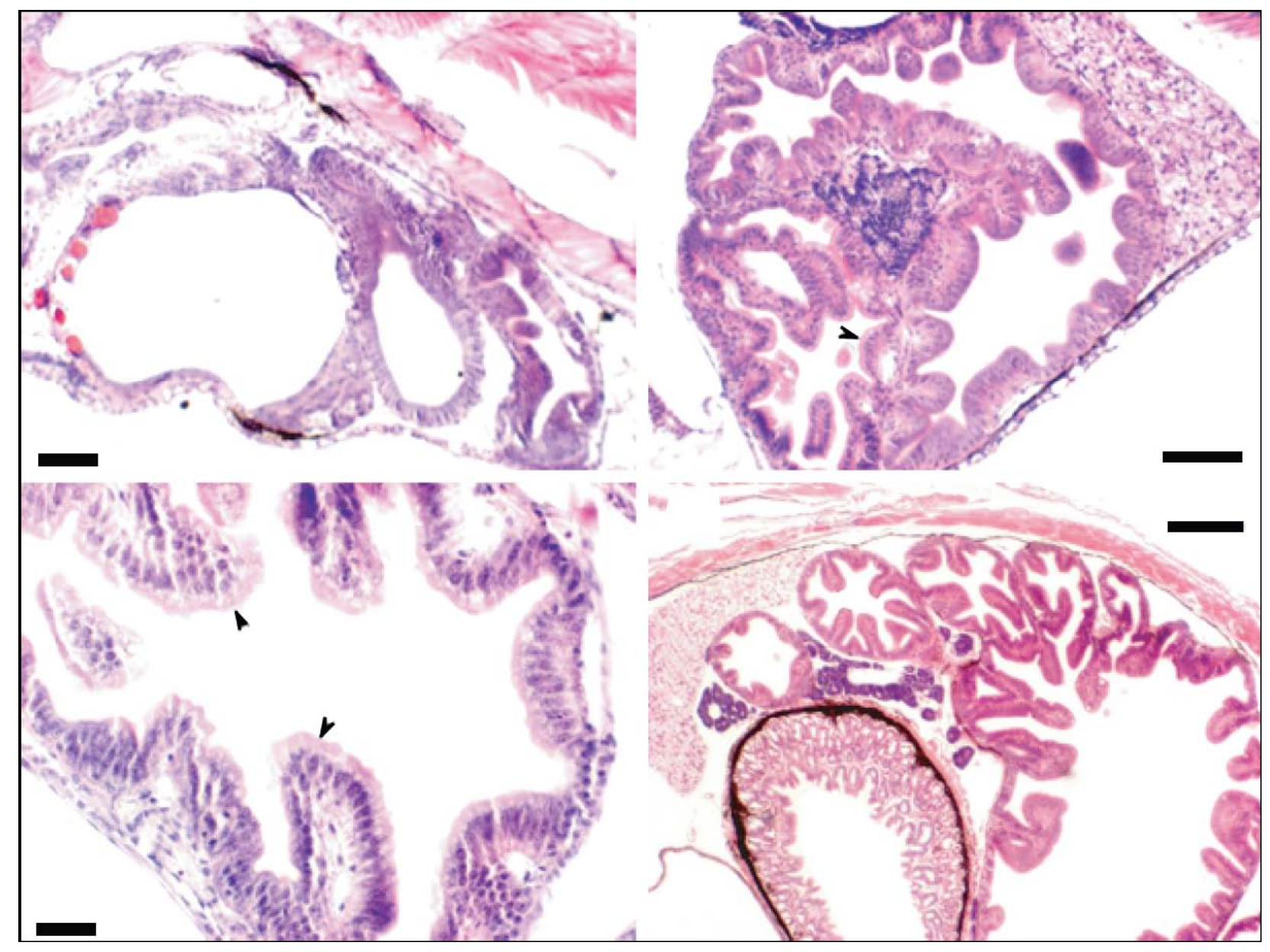

Fig. 4. Histological sections of accessory digestive glands in large yellow croaker larvae (H-E). (a) Sagittal section of a larva at $4 \mathrm{dph}$, showing the development of the liver. Scale bar $=150 \mu \mathrm{m}$. (b) Sagittal section of diffused pancreas of a larva at $5 \mathrm{dph}$. Note the presence of eosinophlic-pigmented granules (zymogen) in the pancreas at this earlier stage of development. Scale bar $=60 \mu \mathrm{m}$. (c) Cross section of the liver and pancreas of a larva at $9 \mathrm{dph}$. Scale bar $=60 \mu \mathrm{m}$. (d) Sagittal section of the pancreas of a larva at $9 \mathrm{dph}$. Scale bar $=60 \mu \mathrm{m}$. (e) Detail of the liver of a larva at $25 \mathrm{dph}$. Note the presence of lipidic inclusions within the hepatocytes. Scale bar $=60 \mu \mathrm{m}$. (f) Cross section of the gallbladder and liver of a larva at $23 \mathrm{dph}$. Scale bar $=150 \mu \mathrm{m}$. AI: anterior intestine; BD: bile duct; ES: oesophagus; F: food item; GB: gallbladder; HV: hepatic portal vein; L: liver; MI: intermediate intestine; N: notochord; PA: pancreas; R: rectum; SB: swim bladder; YS: yolk sac.

\section{DISCUSSION}

Similarly to most marine finfish species, newly hatched large yellow croaker had an undifferentiated and undeveloped digestive tract and accessory organs. The opening of the mouth, and therefore the start of exogenous feeding determinates regional gut differentiation in most teleost species (Iwai \& Tanaka, 1968; Stroband et al., 1979; Stroband \& Kroon, 1981; Boulhic \& Gabaudan 1992; Sarasquete et al., 1995; Gisbert et al., 2004). In large yellow croaker, 
five distinctive histologically regions: buccopharynx, oesophagus, pre- and postvalvular intestine, and rectum were observed at the onset of exogenous feeding phase ( $3 \mathrm{dph}, 4.1 \pm 0.1$ $\mathrm{mm} L_{\mathrm{T}}$ ). The early differentiation and regionalization of the digestive tract in such a short period of time is a common feature of marine finfish species developing from small pelagic eggs, since yolk-sac reserves are depleted soon after hatching, and larvae need to start to feed exogenously at early stages of development.

From hatching until close to $3 \mathrm{dph}$, large yellow croaker larvae depended exclusively on their yolk-sac reserves, while a period of mixed nutrition based on endogenous reserves and live preys (rotifers) was noted up to 5-6 dph $\left(4.3 \pm 0.1 \mathrm{~mm} L_{\mathrm{T}}\right)$. This period is considered as one of the most critical events during larval early life stages, since short delays in feed availability influence posterior larval growth and survival. In Chinese hatcheries, the transition from endogenous to exogenous nutrition often results in high mortalities of large yellow croaker larvae, which might be attributed to nutritional and/or infection problems. Different authors have implicated bacteria with problems of larval rearing in different finfish species (Gatesoupe, 1982, 1990; Nicolas et al., 1989; Padrós et al., 1993; Gisbert et al., 2004). In this sense, the use of emulsion oils to enrich live preys with adequate levels of essential fatty acids might be a via of introduction of pathogenic bacteria into the larval rearing system (Perez Benavente \& Gatesoupe, 1988; Gatesoupe, 1990). In the current study, the presence of functional oesophageal goblet cells secreting mucins, which are known to play an important role in protecting the mucosa against bacterial attack and, physical and chemical damage (Allen, 1989), added to the fact that no histopathological alterations, nor bacteria were detected in the digestive system mucosa and lumen, respectively, seemed to indicate that such high mortality rates during larval rearing of large yellow croaker, particularly throughout the stages of first feeding when larvae undergo intense organogenesis, might be linked to nutritional causes rather than to infection problems. However, further research is needed to verify the above-mentioned hypothesis. 
As previously mentioned, in large yellow croaker, oesophageal mucous cells developed between 4 and 5 dph during the transition from endogenous to exogenous feeding. The differentiation of oesophageal mucous cells is a species-specific process in marine teleosts, which normally tales place coinciding with the onset of exogenous feeding, as it has been noted for large yellow croaker (present study), Solea solea L. (Boulhic \& Gabaudan, 1992), Paralichthys dentatus L. (Bisbal \& Bengtson, 1995), Pleuronectes ferruginea (Storer) (Baglole et al., 1997) and S. senegalensis Kaup, 1858 (Ribeiro et al., 1999), or at later stages of development, as observed in Scophthalmus maximus L. (Cousin \& Baudin-Laurencin, 1985), Melanogrammus aeglefinus (L.) (Hamlin et al., 2000) Paralabrax maculatofasciatus (Steindachner, 1868) (Peña et al., 2003) and P. californicus (Ayres) (Gisbert et al., 2004). The reasons for such different schedules in the oesophagus development remain not clear, but they might be related to the different ecology, feeding habits and/or taxonomical position of species.

Although a stomach anlage appeared in large yellow croaker soon after first feeding, the development of gastric glands in the cardiac stomach, as well as the presence of neutral mucosubstances within stomach mucous cells, which protect the digestive mucosa from autodigestion processes caused by hydrochloric acid and enzyme secretions produced by gastric glands, suggested that the stomach was not functional until $21 \mathrm{dph}\left(9.2 \pm 1.2 \mathrm{~mm} \mathrm{~L}_{\mathrm{T}}\right)$. Prior to the development of gastric glands, large yellow croaker larvae mainly relied in the pancreas and intestine for the digestion and absorption of nutrients. The presence of acidophilic supranuclear vacuoles in the postvalvular intestine soon after the onset of exogenous feeding indicated the presence of pinocytotic absorption and intracellular protein digestion. Pinocytosis and intracellular digestion have been proposed as the main mechanism for protein absorption in larvae during the absence of a functional stomach (Govoni et al., 1986). During this period, the prevalvular intestine has been described as the main site of the larval digestive tract for extracellular proteolytic digestion due to its alkaline $\mathrm{pH}$ and the presence of trypsin secreted from 
the exocrine pancreas (Walford \& Lam, 1993; Zambonino Infante \& Cahu, 2001). Once the stomach diffentiated, the incidence of supranuclear vacuoles in the intestinal mucosa of large yellow croaker decreased, as a result from a change in the protein digestion mechanisms. In this sense, the secretion of both hydrochloric and enzymes produced by gastric glands might reduce the pinocytotic activity and intracellular digestion by intestinal cytosolic enzymes (Cahu \& Zambonino Infante, 2001) promoting extracellular protein digestion (Govoni et al. 1986). This change in protein digestion mechanisms associated to the differentiation of the stomach is indicative of the transition from a larval to a juvenile digestive physiology and nutrition (Tanaka 1971; Govoni et al., 1986).

In most teleosts, the anterior intestine is involved in the absorption of lipids and it is characterized by lipid inclusions in the epithelial cells of the mucosa, which are considered as a temporary storage site (Iwai \& Tanaka, 1968; Stroband \& Kroon 1981; Rombout et al., 1984; Kjorsvik et al., 1991). In the present study, no lipid inclusions were observed in the anterior segment of the intestinal mucosa of large yellow croaker, although lipid vacuoles increased in the liver throughout development. These results are similar to those already reported in $P$. californicus (Gisbert et al., 2004) and Hipoglossus hipoglossus (Linnaeus, 1758) (Luizi et al., 1999). The above-mentioned authors suggested that the lack of such lipid vacuoles in the intestine of Artemia-fed larvae could be interpreted as a sign of reduced intestinal lipid digestion due to the rapid passage of Artemia through the alimentary canal of larvae (Luizi et al., 1999); whereas, Gisbert et al. (2004) hypothesized that the lipid content of feed did not exceed the fatty acid absorption and exporting capacities of enterocytes, resulting in no accumulation of lipids in the intestinal mucosa.

The complete differentiation of the digestive system in large yellow croaker was achieved with the differentiation of pyloric caeca and gastric glands between 17 and $21 \mathrm{dph}$, indicating the end of the larval period and the transition to the juvenile stage. The latest differentiation of the 
above-mentioned structures in this species was in accordance with other teleosts species (Govoni et al. 1986; Segner et al. 1993; García Hernández et al., 2001; Gisbert et al., 2004). The lack of a glandular stomach has generally been considered as a limiting factor in feeding larvae with compound diets (Dabrowski, 1984; Segner et al., 1993; Bagogle et al., 1997). However, recent studies have showed that it is possible to start feeding Dicentrarchus labrax L. larvae with these kinds of diets (Cahu et al., 2003). Thus, the late differentiation of a functional stomach in large yellow croaker should not prevent weaning larvae onto a dry diet until metamorphosis, and further studies must be conducted to determine the best moment to feed larvae with compound diets.

In conclusion, the ontogenetic development of the digestive system in large yellow croaker followed the pattern in marine species described thus far, although there existed some differences in the differentiation time between different species, which reflect variations in the factors affecting larval development, such as egg size, incubation temperature, breeding conditions, larval nutrition or genetic origin. Further studies comparing the development and functionality of the digestive system of larvae fed different diets (i.e. compound vs. live feed) will enable a better understanding of the required feeding procedures and rearing protocols.

\section{AKNOLEDGEMENTS}

This study was supported in part by French-Chinese cooperation, PRA BT 01-03.

\section{References}

Allen, A. (1989). Gastrointestinal mucus. In: Schultz, S.G., Forte, J.G. \& Raumer, B.B. (Eds.), Handbook of Physiology. Section 6. The gastrointestinal lumen, pp. 359-382. Bethesda: American Physiological Society. 
AOAC, (1990). Official methods of analysis of the Association of Official Analytical Chemists. $15^{\text {th }}$ Edition. Arlington, VA: Association of Official Analytical Chemists.

Bagogle, C. J., Murray, H. M., Goff, G. P. \& Wright, G. M. (1997). Ontogeny of the digestive tract during larval development of yellowtail flounder: a light microscopic and mucous histochemical study. Journal of Fish Biology 51, 120-134.

Bell, J. G., McEvoy, L. A., Estevez, A., Shields, R. J. \& Sargent, J. R. (2003). Optimising lipid nutrition in first-feeding flatfish larvae. Aquaculture 227, 211-220.

Bisbal, G. A. \& Bengtson, D. A. (1995). Development of the digestive tract in larval summer flounder. Journal of Fish Biology 47, 227-291.

Boulhic, M. \& Gabaudan, J. (1992). Histological study of the organogenesis of the digestive system and swim bladder of Dover sole, Solea solea L. Aquaculture 102, 373-396.

Cahu, C. L. \& Zambonino Infante, J. L. (2001). Substitution of live food by formulated diets in marine fish larvae. Aquaculture 200, 161-180.

Cahu, C. L., Zambonino Infante, J. L. \& Barbosa, V. (2003). Effect of dietary phospholipid level and phospholipid:neutral lipid value on the development of sea bass (Dicentrarchus labrax) larvae fed a compound diet. British Journal of Nutrition 90, 21-28.

Cousin, J. C. B. \& Baudin-Laurencin, F. (1985). Morphogenese de l'appareil digestif et de la vessie gazeuse du turbot, Scopththalmus maximus L. Aquaculture 47, 305-319.

Dabrowski, K. (1984). The feeding of fish larvae: present state of art and perspectives. Reproduction Nutrition Development 24, 807-833.

García Hernandez , M. P., Lozano, M. T:, Elbal, M. T. \& Agulleiro, B. (2001). Development of the digestive tract of sea bass (Dicentrarchus labrax L.). Light and electron microscopic studies. Anatomy and Embriology 204, 39-57. 
Gatesoupe, J. (1982). Nutritional and antibacterial treatments on live food organisms: the influence on survival, growth rate and weaning success of turbot Scopththalmus maximus. Annales du Zootechnie 31, 353-368.

Gatesoupe, J. (1990). The continuous feeding of turbot larvae, Scopththalmus maximus, and control of the bacterial environment of rotifers. Aquaculture 89, 139-148.

Gisbert, E., Piedrahita, R. H. \& Conklinm D. E. (2004). Ontogenetic development of the digestive system in California halibut (Paralichthys californicus) with notes on feeding practices. Aquaculture 232, 455-470.

Govoni, J. J., Boehlert, G. W. \& Watanabe, Y. (1986). The physiology of digestion in fish larvae. Environmental Biology of Fishes 16, 59-77.

Hamlin, H. J., Hunt von Herbing, I. \& King, L. J. (2000). Histological and morphological evaluations of the digestive tract and associated organs of haddock throughout posthatching ontogeny Journal of Fish Biology 57, 716-732. doi:10.1006/jfbi.2000.1347

Hong, W. \& Zhang, Q. (2003). Review of captive bred species and fry production of marine fish in China. Aquaculture 227, 305-318.

Iwai, T. (1967). The comparative study of the digestive tracts of teleosts larvae - I. Fine structure of the gut epithelium in larvae of ayu. Bulletin of Japanese Society of Scientific Fisheries 33, 489-496.

Luizi, F. S., Gara, B., Shields, R. J. \& Bromage, N. R. (1999). further description of the development of the digestive organs in Atlantic halibut (Hippoglossus hippoglossus) larvae, with notes on differential absorption of copepod and Artemia prey. Aquaculture 176, 101-116.

Masuda, H., Amaoka, K., Araga, C., Uyeno T. \& Yoshino, T. (1984). The fishes of the Japanese Archipelago. Vol. 1 (text). Tokyo, Japan: Tokai University Press. 
Nicolas, J. L., Robic, E. \& Asquer, D. (1989). Bacterial flora associated with a trophic chain consisting of microalgae, rotifers and turbot larvae: influence of bacteria on larval survival. Aquaculture 83, 237-248.

Padrós, F., Minkoff, G., Sala, R. \& Crespo, S. (1993). Histological events throughout the development of turbot (Scophthalmus maximus L.) larvae. Journal of Comparative Pathology 109, 321-334.

Peña, R., Dumas, S., Villalejo-Fuerte, M. \& Ortiz-Galindo, J. L. (2003). Ontogenetic development of the digestive tract in reared spotted sand bass Paralabrax maculatofasciatus larvae. Aquaculture 219, 633-644.

Perez Benavente, G. \& Gatesoupe, J. (1988). Bacteria associated with cultured rotifers and artemia are detrimental to larval turbot, Scophthalmus maximus L. Aquaculture Engineering 7, 289-293.

Ribeiro, L., Sarasquete, C. \& Dinis, M. T. (1999). Histological and histochemical development of the digestive system of Solea senegalensis (Kaup, 1858). Aquaculture 171, 2293-2308.

Sarasquete, M. C., Polo, A. \& Yúfera, M. (1995). Histology and histochemistry of the development of the digestive system of larval gilthead seabream, Sparus aurata L. Aquaculture 130, 79-92.

Segner, H., Röch, R., Verreth, J. \& Witt, U. (1993). Larval nutritional physiology: studies with Clarias gariepinus, Coregonus lavaraetus and Scophthalmus maximus. Journal of World Aquaculture Society 24, 121-134.

Stroband, H. W. J. \& Kroon, A. G. (1981). The development of the stomach in Clarias lazera and the intestinal absorption of protein macromolecules. Cell Tissue Research 215, 397415. 
Tanaka, M. (1971). Studies on the structure and function of the digestive system in teleosts larvae. III. Development of the digestive system during postlarval stage. Japanese Journal of Ichthyology 18, 164-174.

Walford, J. \& Lam, T. J. (1993). Development of the digestive tract and proteolytic enzyme activity in seabass (Lates calcifer) larvae and juveniles. Aquaculture 109, 187-205.

Zambonino Infante J.L. \& Cahu C., 2001. Ontogeny of the intestinal tract of marine fish larvae. Comparative Biochemistry and Physiology 130, 477-487.

Zheng, Z. Y., Su, Y. Z., You, L. \& Weng, Z. C. (1996). Experiment of effects of nutritionintensified rotifer on growth and survival rate of larval yellow croaker, Pseudosciaena crocea. Chinese Journal of Oceanography in Taiwan Strait 15, 7-10. (in Chinese) 